\title{
Retratos e conflitos de missionários ocidentais na Turquia: análise da revista Adventist Frontiers*
}

\author{
Rodrigo Follis" \\ Samir Domingues Costa ${ }^{* * *}$
}

\section{Resumo}

O presente artigo analisa parte dos discursos da revista Adventist Frontiers quanto aos conflitos vividos por missionários adventistas do sétimo dia na Turquia. O objetivo foi discutir como esses conflitos estão registrados para, assim, perceber qual construção esses missionários, em sua maioria ocidentais, fazem da cultura, religião e sociedade asiática, principalmente em sua vertente islâmica. Também foi possível traçar um breve relato das dificuldades e conflitos vividos por esses missionários em uma cultura diferente da sua, o que possibilitou perceber quais são, na visão editorial, os apelos e estereótipos construídos sobre a cultura e religiosidade asiática que melhor fazem eco dentro da cultura ocidental. A partir dessa análise, foi possível levantar uma importante discussão que considere como se dá o processo de colonização de parte do pensamento teológico ao se relatar e construir um ethos sobre o "eu" e o "outro". Assim, a discussão se deu a partir de uma análise documental, com abordagens quantitativas e qualitativas. O resultado encontrado foi um misto de evolução do encontro e junção com o outro, em associação com um estranhamento a respeito de quem é esse outro e quem o missionário espera que ele seja após tais encontros.

Palavras-chave: Conflitos. Turquia. Adventismo. Missiologia.

\section{Pictures and conflicts of missionaries in Turkey: an analysis of the Adventist Frontier Magazine}

\footnotetext{
Abstract

The present article analyzes part of the discourse of the Adventist Frontiers Magazine regarding the conflicts lived by Seventh-day Adventist missionaries in Turkey. The

* Esse periódico é publicado pela Adventist Frontier Missions Inc., com circulação mensal de 20 mil exemplares.

** Doutor em Ciências da Religião e Professor do UNASP.

*** Mestrando em Ciências da Religião pela PUC/Campinas.
} 
objective was to discuss how these conflicts are registered, in order to perceive what is the construction that these missionaries, Westerns in their majority, make of the culture, religion and society in Asia, especially in its Islamic side. It was also possible to draw a brief report of the difficulties and conflicts experienced by those missionaries in a culture different than their own. The goal of the magazine, corpus of this present study, is to narrate stories that show an intercultural religious view, aiming sponsorships that help the missionaries to keep their projects functioning. This enabled to perceive what are, in the editorial view, the pleas and stereotypes built on the Asian culture and religiosity, that make more echoes in the Western culture. From this analysis, it was possible to raise an important discussion that considers how the process of colonization of part of the theologian thinking is given, by reporting and constructing an ethos on the "I" and the "other". Therefore, the discussion was given through a documental analysis, with quantitative and qualitative approaches, being built charts to quantify the data, but also more open classifications, that show the way to these materials. The result was a mixture of evolution of the encounter and junction of the other, in association with a estrangement about who is this other and who is the one that the missionary expects this other will be after these encounters.

Keywords: Conflicts. Turkey. Adventism. Missiology.

\section{Retratos y conflictos de misioneros en Turquía: análisis de la Revista Adventist Frontiers}

\section{Resumen}

El presente artículo analiza parte de los discursos de la revista Adventist Frontiers en cuanto a los conflictos vividos por misioneros adventistas del séptimo día en Turquía. El objetivo fue discutir cómo dichos conflictos están registrados para entender qué tipo de construcción hacen de la cultura, religión y sociedad asiáticas dichos misioneros, en su mayoría occidentales, principalmente en su vertiente islámica. También fue posible trazar un breve relato de las dificultades y conflictos vividos por dichos misioneros en una cultura diferente a la propia. El objetivo de la revista, corpus del presente análisis, es narrar historias que contemplen una visión religiosa intercultural, en búsqueda de patrocinadores para que dichos misioneros continúen en sus proyectos, lo que hizo posible vislumbrar cuales son, en la visión editorial, las necesidades y estereotipos percibidos acerca de la cultura y religiosidad asiáticas que hacen mejor eco dentro de la cultura occidental. A partir de dicho análisis, fue posible levantar una importante discusión que consideró el cómo se da el proceso de colonización por parte del pensamiento teológico al relatarse y elaborar un ethos sobre el "yo" y el "otro". Así, la discusión se dio a partir de un análisis documental, con abordajes cuantitativos y cualitativos, construyéndose tablas para cuantificar los hallazgos, pero también clasificaciones más abiertas que muestren el camino de ellos. El resultado hallado fue una mezcla de evolución del encuentro y unión con el otro en asociación con un alejamiento sobre quién es ese otro y quien el misionero espera que el otro sea después de dichos encuentros.

Palabras clave: Conflictos. Turquía. Adventismo. Misionologia. 


\section{Introdução}

A história do cristianismo mostra que a afirmação do seu papel na sociedade sempre foi um desafio. O momento atual da sociedade parece ser o de clamar por mais igualdade e equidade, e isso aparentemente mostra que o paradigma do Sermão do Monte, proferido por Cristo, deveria ser dominante no cristianismo (Mt 5-7), afinal, esse discurso dá ao outro o papel principal na construção de uma sociedade. Dentro dessa concepção, não existe espaço para um pensamento colonialista na práxis missionária cristã. Hoje, é imprescindível que haja uma busca em entender e aceitar o "outro". É nessa esteira que Giorgio Agamben (2010, p. 61) afirma que "somente através do reconhecimento dos outros, o homem pode constituir-se como pessoa". Então, a construção do ethos, ${ }^{1}$ a fim de preservar a sobrevivência do cristianismo, se torna o caminho mais relevante a se considerar dentro de uma teoria que dê conta de analisar pensamentos e interações religiosas interculturais e inter-religiosas. E são esses aspectos que o presente artigo busca teorizar a partir de um relato empírico/documental.

Para ficar mais claro o objetivo que aqui tencionamos abordar, alguns esclarecimentos precisam ser feitos para, então, delinearmos a problemática a ser tratada. Primeiramente, precisamos definir o que entendemos por missionários inter-religiosos, explicar como o adventismo do sétimo dia contribui para as discussões e práticas desse grupo para, com isso, introduzirmos uma das ações missionárias feita pelos adventistas, a qual analisaremos a partir do conceito do ethos "eu-outro", que também delimitaremos no presente estudo.

Para começarmos, é importante deixar claro um pressuposto: a construção de nossa identidade sempre se dará para além da definição do "eu" como indivíduo. É claro que pensar o "eu" é um processo deveras importante, mas ele não é o fim do processo de construção identitária. Afinal, no "eu" temos apenas parte da constituição da identidade. O "eu", dentro de uma concepção mais ampla, deve sempre ser visto como parte da busca e do entendimento pelo/do "outro". Não existe o "eu" sem esse “outro" para ajudar na delimitação e também na própria afirmação desse "eu”. Dentro dessa lógica, a constituição da identidade sempre será algo que demandará conflitos e fronteiras, ${ }^{2}$ e será recheada de arestas a serem arrumadas, articuladas ou mesmo ignoradas.

Para melhor compreensão da construção do termo ethos, ver Lessa et al. (2016).

2 Pode-se definir o termo "fronteira" aqui como um conceito que avança para os domínios da construção simbólica de pertencimento denominado identidade, definido pela diferença e alteridade na relação com o outro (ver PESAVENTO, 2001; MARTINS, 1997). 
Na obra Perspectivas no movimento cristão mundial, é possível observar uma descrição bem aprofundada dessa relação "eu" e o "outro" dentro da religião cristã, em sua vertente missionária. Os autores desse compêndio compartilham o longo trajeto da humanidade em se envolver com o ato de servir e/ou mesmo de colonizar o "outro". A história dos últimos séculos, em especial, descreve o comportamento de missionários, assim como, os objetivos que eles alcançaram dentro de suas buscas, por narrar a pessoas distintas quais as crenças que os levaram até aquele local distante de sua realidade social (WINTER; HAWTHORNE; BRADFORD, 2009). Dentro dessa história, desenvolveu-se ao final do século XVIII um forte movimento religioso com pessoas dispostas a servirem como missionárias. ${ }^{3}$ Isso se deu principalmente por causa do descobrimento do chamado Novo Mundo e da vinda do protestantismo para a América do Norte. É verdade que as sociedades missionárias já existiam nos principais países protestantes da Europa, mas foi na década de 1880 que houve um destaque maior em relação a esse movimento nos Estados Unidos da América (BOSCH, 2002, p. 395). David Bosch ${ }^{4}$ descreve de maneira detalhada algumas características dessas sociedades (2002, p. 396):

[...] Um número crescente dessas novas sociedades engajou-se na causa das missões no exterior. Fundamentalmente, as sociedades se estruturavam todas com base no princípio do voluntariado e dependiam da contribuição, em termos de tempo, dedicação e dinheiro, de seus membros.

A história da Igreja Adventista do Sétimo Dia ${ }^{5}$ (IASD), que se originou nos Estados Unidos, no século XIX, também se cruza com esse movimento das sociedades missionárias que se fortalecia, ocorrendo nesse período a

3 Entende-se por "missionário", naquele momento histórico do protestantismo, todo membro regular da denominação que, sem fins lucrativos, se dispõe voluntariamente a dedicar horas regulares em diversas necessidades (interesse teológico e/ou humanitário) que essas sociedades (posteriormente se tornaram instituições) tinham como desafios ao redor do mundo.

4 David Jacobus Bosch (2002) foi um dos mais influentes missiólogos da teologia protestante. Sua principal contribuição se encontra no seu livro Missão transformadora: mudanças de paradigma na teologia da missão.

5 Para saber mais sobre o adventismo, ver: Bull e Lockhart (2007), Gaustad (1986), Greenleaf (2011), Knight; (2000; 2005; 2015), Loughborough (2014); Schünemann (2002), Schwarz e Greenleaf (2016). 
expansão da IASD para outros continentes, inclusive o asiático. Em sua definição oficial ${ }^{6}$ de quem são, a denominação adventista se define como:

Os adventistas do sétimo dia, com mais de 20 milhões de membros no mundo, são uma igreja cristã protestante organizada em 1863 nos Estados Unidos. Sua origem ocorre logo depois do movimento liderado por Guilherme Miller, que ressaltou a necessidade de maior ênfase na pregação sobre a breve volta de Jesus Cristo a este mundo.

Com o passar dos anos, a IASD chegou a ser uma das denominações cristãs que mais enviaram missionários para países fora da América do Norte (FOLLIS, 2017, p. 111-116). Devido a isso, o movimento missionário adventista se fortaleceu muito, tendo nos voluntários norte-americanos que saíram para outros países a fim de pregar sobre a mensagem bíblica uma de suas maiores forças por muitos anos.

Depois de um longo processo de crescimento e fortalecimento do ímpeto missionário dentro da administração da IASD mundial, em 1985 um grupo de estudantes fundou uma sociedade denominada Adventist Frontier Missions $^{7}$ (AFM), com o intuito de ir aos lugares mais remotos do planeta Terra, levando a mensagem adventista. Sem estar ligado administrativamente à IASD, esse grupo se considera unido ao adventismo em seu propósito fundante, história e objetivos finais. O principal objetivo dos missionários da AFM é estabelecer uma congregação adventista nos locais por onde passam. Para alcançar esse alvo, por um lado eles articulam doações de empresários, membros da denominação e simpatizantes, e por outro lado os voluntários são preparados para morarem dentro da comunidade, aprenderem a língua nativa, assimilarem a cultura e compreenderem as fronteiras criadas pelo fazer religioso em seu país de destino. Quando chegam ao novo país, eles

\footnotetext{
${ }_{6}$ Essa definição se encontra no site oficial da IASD em língua portuguesa. Disponível em: <https://www.adventistas.org/pt/institucional/os-adventistas/quem-sao-os-adventistas/>. Acesso em: 24 set. 2018.

7 É válido registrar que um dos autores do presente artigo é filiado à AFM, tendo sido missionário na Turquia por alguns anos e, atualmente, trabalha no escritório regional do Brasil. Não acreditamos, entretanto, que essa proximidade seja negativa para a análise crítica do presente artigo; muito ao contrário, ela consegue alcançar detalhes que sem essa vivência não seriam possíveis analisar (ver TERRIN, 1998; ALVES, 2005). Assim como consideramos válida essa análise mais próxima, também cremos que uma análise de um par não envolvido tão diretamente no processo também seria muito bem-vinda para as discussões sobre a relevância (ou não) dos trabalhos desenvolvidos.
} 
buscam se aproximar do povo e fazer amizades, com o intuito de criar uma construção do ethos ("eu" com o "outro"). Então, dentro desse processo de construção de uma imagem, os missionários usam o que aprenderam para montar estratégias de evangelismo ${ }^{8}$ adaptadas à cultura local. Por fim, quando um indivíduo daquela etnia compreende a mensagem apresentada, os missionários passam a fazer um trabalho de preparação, no qual treinam esses conversos para que se tornem líderes da nova congregação adventista local e, assim, possam continuar a levar a mensagem aos seus compatriotas. Dessa forma, o resultado esperado é o estabelecimento de uma igreja que dê continuidade ao trabalho iniciado pelos missionários, buscando-se criar uma igreja verdadeiramente nativa.

A AFM tem desenvolvido, desde o início de suas atividades, uma revista mensal, a Adventist Frontiers, que visa narrar histórias dos seus missionários. Nela se busca contemplar uma visão religiosa intercultural, ao mesmo tempo em que se procuram patrocínios para que esses voluntários continuem a trabalhar e para que mais missionários possam ser enviados a outros países. Inicialmente, a revista era publicada trimestralmente, e hoje ela é mensal.

Entre os 21 países onde a AFM trabalha atualmente está a República da Turquia, localizada entre a Europa e a Ásia e rodeada por oito países. Por ser muito rica em história religiosa e bíblica, a Turquia foi classificada como o sexto destino turístico mais popular do mundo em 2013. Quanto à religião, embora a Turquia seja um Estado laico, isto é, sem uma religião oficial, a maioria da população é muçulmana (GIMARAIS, 2007, p. 13-18), o que torna o trabalho da AFM especial nesse contexto "não cristão". Há mais de uma década, a AFM envia voluntários para a Turquia, e estes têm relatado mensalmente na revista Adventist Frontiers suas histórias de aprendizagem, conflitos e adaptação à cultura.

O presente artigo se propõe a analisar parte dos discursos da revista Adventist Frontiers quanto aos retratos e conflitos vividos por esses missionários adventistas na Turquia. O objetivo é discutir como esses retratos e conflitos estão registrados, a fim de perceber que construção esses missionários, em sua maioria ocidentais, fazem da cultura, da religião e da sociedade oriental, especialmente em sua vertente islâmica. Além disso, foi traçado um breve relato das dificuldades vividas por esses missionários em uma cultura diferente da sua. Como o intuito da revista é buscar patrocinadores, conforme já

Para melhor compreensão do termo “evangelismo”, ver Molina (2017). 
explicado, foi possível também perceber quais são, na visão editorial, os apelos e estereótipos construídos sobre a cultura e religiosidade asiáticas que melhor fazem eco dentro da cultura ocidental. Assim, a partir dessa análise, foi investigado como se dá o processo de compartilhar parte do pensamento teológico adventista no relato e construção de um ethos, sobre o "eu" e o "outro".

Com esse objetivo em mente, este artigo se dividirá da seguinte maneira: primeiro abordaremos mais detidamente nossa metodologia, depois disso teremos um momento de teorização sobre o conceito de "eu-outro" e dos conflitos inerentes a essa realidade. Em um terceiro momento, poderemos analisar a revista corpus do presente trabalho. Por último, tiraremos algumas considerações sobre o que aqui discutimos, abrindo espaço para futuras análises e pensamentos a partir dos achados aqui listados.

\section{Metodologia}

Adaptando a metodologia proposta em Follis (2017), o presente artigo propõe uma combinação de duas formas de metodologia. Na primeira, abordamos teoricamente conceitos sobre o "eu" e o "outro", assim como, quanto ao processo de colonização da práxis missiológica devido a um pensamento imperialista por parte de missionários (voluntários ou não); tais discussões se deram por meio de uma pesquisa bibliográfica em alguns autores-chave a serem abordados na seção seguinte. Já na segunda parte metodológica, que compõe o presente artigo, o foco esteve na catalogação e análise de uma fonte documental. $\mathrm{O}$ corpus foi a revista Adventist Frontiers que, como vimos, é produzida mensalmente pela AFM, sendo a principal plataforma de comunicação entre os missionários voluntários e os patrocinadores da agência.

Essa segunda parte foi igualmente dividida em duas subpartes. A primeira teve na escola da Análise de Conteúdo sua ancoragem, a qual foi transcrita por meio de tabelas quantitativas (FRANCO, 1986; BARDIN, 1977). A análise foi disposta em anos, devido à grande quantidade de material, ficando mais simples de se visualizar as tendências. O período pesquisado foi da primeira edição de 2007 até a última edição de 2017, contemplando um tempo histórico de mais de uma década de análise. O objetivo foi incluir um largo período para que se percebessem tendências mais consolidadas acerca do uso dos termos e dos tópicos ligados a eles dentro da instituição religiosa adventista, e mais precisamente da AFM. Nas tabelas temos tanto categorias 
mais amplas quanto categorias mais específicas de análise, que tentam agrupar as temáticas da maneira mais organizada possível, já podendo vislumbrar algumas tendências dos assuntos abordados (STRAUSS; CORBIN, 2008).

Quanto à segunda subparte, após a catalogação geral, selecionaramse alguns excertos textuais para uma análise qualitativa. Aqui o intuito foi buscar o sentido dos termos encontrados, relacionados aos conflitos e retratos vividos pelos missionários da AFM na Turquia, comparando tudo à teorização que foi realizada na primeira parte. Assim, buscamos entender os conteúdos das figuras de linguagem, reticências, entrelinhas e até mesmo os temas claramente manifestos, tendo na Análise de Discurso nosso abalizamento teórico (ROCHA; DEUSDARÁ, 2005). Neste momento, é importante salientar que as tabelas foram comparadas dentro do desenvolvimento histórico em que as citações se encontram, isso por meio do ano de publicação da revista, o que indicaria um desenvolvimento cronológico do pensamento dos missionários e da linha editorial do periódico. As análises qualitativas inseridas durante o texto, por sua vez, foram escolhidas por ordem de importância e em método não probabilístico.

A fonte da pesquisa foi um período bem representativo, o que foi possível devido ao acesso on-line ao acervo da revista, permitindo a pesquisa digital dos dados do presente estudo. Com isso, o desenvolvimento da análise, resumidamente, se deu da seguinte forma:

1. Entrou-se no website: http://www.afmonline.org/resources/ourmagazine.

2. Pesquisou-se página por página, por meio dos arquivos em formato PDF baixados, todos os relatos de missionários que viveram na Turquia. Entre essas histórias, foram selecionadas apenas aquelas nas quais havia um claro conflito "eu-outro", seja ele ético, físico, moral, social, econômico e/ou religioso.

- Após uma primeira leitura dos textos, empreendeu-se uma segunda leitura, agora para que fossem desenvolvidas tabelas quantitativas a fim de traçar as tendências encontradas.

- Também se produziu uma tabela que pode ser considerada um misto entre quantitativa e qualitativa, na qual registramos quatro grandes categorias que acreditamos mostrarem as tendências gerais dos achados. 
3. Por último, escolheram-se alguns excertos para serem analisados textualmente no presente artigo. Não objetivamos, nessa última parte, ser censitários, mas apenas demonstrar a tendência que acreditamos ter sido encontrada nas análises anteriores.

É importante salientar que se optou, em toda esta pesquisa, por não referenciar, ao final do texto, citações de artigos e reportagens encontradas na revista Adventist Frontiers. Essa opção se deu por esse material não ser considerado primariamente como referência, mas como objeto/fonte deste estudo. Com isso, foi evitado também um aumento desnecessário das referências ao final do artigo. Porém, todas as informações (mês, ano e página) para se encontrar as citações foram disponibilizadas diretamente no corpo do presente artigo. Além disso, sempre que se usou uma reportagem, notícia ou artigo retirado da revista Adventist Frontiers, ocultou-se qualquer menção ao autor responsável pelo texto. Essa informação aparece na maioria das vezes na revista, mas não foi utilizada nesta pesquisa. Assim, optamos pelo fato de os nomes dos autores serem fictícios, isso devido a questões de segurança, já que nessas regiões inter-religiosas esses autores/missionários podem sofrer perseguições devido à sua crença religiosa. Essa realidade em nada inviabiliza a pesquisa, pois o que importa é o conteúdo e a tendência do grupo, e não os indivíduos-autores. Desse modo, o objetivo foi entender a evolução do tema e algumas implicações que podemos dela derivar, principalmente a partir da discussão teórica elencada a seguir.

\section{Retratos e conflitos no paradigma missionário}

Analzira Nascimento (2013) realizou um estudo no qual propõe a necessidade de uma descolonização do paradigma missiológico. Para a autora, é importante salientar a relação que levantamos como pressuposto inicial já na introdução deste trabalho: a relação de retratos e conflitos do "eu" com o "outro" sempre ocorrerão e serão utilizados de maneira significativa dentro das construções identitárias e de demarcação das fronteiras que demonstram quando o "eu" termina e quando o "outro" começa. Entretanto, como um alerta, a pesquisa de Nascimento (2013) descreve a insistência do "eu" em continuar seu programa de expansão, precisando para isso negar a identidade do "outro". Nas palavras da autora: 
Eu ainda ficava intrigada com uma questão: por que alguns cristãos sinceros e bem-intencionados, preocupados com a situação espiritual ou mesmo com todos os aspectos da vida do ser humano, continuam reproduzindo uma prática missionária caracterizada como "os superiores que sabem e podem resolver os problemas do 'outro' e decidir o que é bom para ele”? Por que até mesmo alguns defensores de um discurso que conclama a igreja contemporânea a se inserir melhor na sociedade e educar o seu olhar para uma interpretação diferenciada quanto aos desafios além dos seus portões, não conseguem construir uma relação dialógica-diaconal e escapar da lógica colonial em seus encontros com o "outro"? (NASCIMENTO, 2013, p. 13).

Um exemplo prático dessa dificuldade em aceitar o "outro", que serve também para se discutir o papel político da identidade, é aquele compartilhado no primeiro capítulo da obra Identidade e diferença: a perspectiva dos estudos culturais, momento em que Kathryn Woodward (2014) aborda como o conflito de guerra ocorrido anos atrás entre croatas e sérvios ainda era usado como justificativa para a animosidade e para a formulação de fronteiras entre o "eu" e o "outro". Essa história mostra claramente que a identidade é algo relacional. Para que a identidade sérvia existisse, ela dependia de algo fora dela, de outra identidade que fosse diferente da sua (no caso, a croata). E isso é algo normal de se esperar dentro desse processo dialógico de construção identitária. Só posso ser croata se existirem aqueles que não são iguais a mim. O problema surge justamente quando esse importante pilar de distinção acaba por justificar a demonização daquele que não sou “eu”. E era justamente essa a questão que dividia croatas e sérvios. Entender que a identidade é marcada pela diferença é algo bom e necessário para entendermos as delimitações das fronteiras sociais. Agora, não se pode justificar, a partir da naturalização das fronteiras, atitudes que levem à exclusão e justifiquem projetos que caminhem para eugenias ou atitudes semelhantes (WOODWARD, 2014, p. 9). Assim como também não faz sentido atribuir a essa teorização fronteiriça uma ideia que justifique um ataque a qualquer noção de evangelização. O que é preciso evitar não é o processo dialógico e de conversas de uma crença com a outra, mas as tendências à colonização de um sobre o outro dentro desse processo evangelizador.

Como narra Bosch (2002, p. 177), durante a história do cristianismo é possível identificar elementos de conflitos para o equilíbrio do ethos. Entre outros fatos, destaca-se o dia 27 de novembro de 1095, em que o papa Urbano II convocou os líderes religiosos franceses a atenderem ao Concílio 
de Clermont. Nesse encontro, o discurso instigava o grupo contra os árabes, detalhando ações a serem realizadas em locais santos. Os franceses foram desafiados a marcharem para o Oriente, a fim de vingarem o sacrilégio dos selvagens árabes e resgatarem as terras santas das mãos deles. Não havia, oficialmente, intenções missionárias ou humanitárias para com os muçulmanos, nem o desejo de pregar o evangelho, mas, sim, resolver uma possível ameaça para o poder eclesiástico. O papa Urbano II não tinha intenção alguma de dialogar com os muçulmanos; ali tínhamos apenas uma ação militar, pois se via o islamismo como uma ameaça que precisava ser aniquilada. A proposta realizada poderia parecer bastante tentadora para muitos, pois a recompensa dos que participassem da missão seria o perdão dos pecados, a certeza do paraíso, novas terras, riquezas e poder.

Narrando um pouco mais à frente na História, Nascimento (2013, p. 66-68) nos lembra do registro de outro conflito. De um lado, aqueles que sempre defenderam a Europa como sendo a detentora da História Antiga, em especial a greco-romana, e de outro os judeus e islâmicos. Os europeus ignoravam o papel desempenhado pelos islâmicos e judeus na história mundial. Na verdade, foi o mundo islâmico-judaico que manteve a herança cultural greco-romana, com suas cidades, comércios, negócios, filosofia e história, enquanto a "Europa Ocidental" era controlada pelo feudalismo. Então, em 1453, com a tomada de Constantinopla pelos turcos, a Europa ficou ilhada pelo mundo muçulmano, que controlava boa parte do Mediterrâneo. Essa condição foi determinante para que os europeus se arriscassem a buscar novas rotas para o comércio. Claro, devido a essa necessidade, acabou-se por descobrir (quase que por acaso) o chamado Novo Mundo, fazendo com que a Europa passasse a exercer um papel ainda maior como protagonista mundial. Assim, nasceu aquilo que Enrique Dussel (1993) chama de "o encobrimento do outro". Para esse autor, precisamos continuar alguns projetos da modernidade (iniciada com as navegações) e abandonar outros. Ela trouxe um interessante conceito emancipador, mas também ajudou a justificar a violência sobre aqueles considerados diferentes (o "outro"), como feito pelos colonizadores europeus perante os índios norte-americanos ou quanto à escravidão africana servindo como mão de obra do Novo Mundo.

Nos primeiros anos do século XX, dentro da história do protestantismo, ocorreu uma mudança na maneira de interpretar a Bíblia, pois a forte ênfase na razão levou a um novo formato de leitura das Escrituras, diminuindo a concepção tradicional da fé e das leituras literalistas. A partir 
dessa mudança epistemológica, os conflitos e diferenças internos acabaram sendo ainda mais acentuados. Essa construção criou grupos religiosos cristãos que enxergavam o "outro" como inferior (BOSCH, 2002, p. 413). É interessante observar que, até hoje, esse comportamento ainda está presente e acaba por nortear muitas das missões e evangelizações, sendo visto tanto quando se prega para outras religiões não cristãs quanto para outras denominações cristãs.

A verdade é que, em diversos momentos da história do cristianismo, essa relação do "eu" com o "outro" deixou marcas negativas, as quais ainda se fazem presentes. Assim, torna-se necessário relembrar constantemente esse histórico, objetivando que esses equívocos sejam minimizados dentro dos novos empreendimentos missionários. Em vista disso, como afirmamos já na introdução deste trabalho, é importante que a mentalidade de colonização esteja cada vez mais afastada da rotina diária da vida de missionários que desejam sinceramente se relacionar com o outro e entregar a eles não uma mensagem colonialista, mas sim uma mensagem que traga libertação (DUSSEL, 1993).

Se os conflitos se iniciam com o "eu" (no caso, aqui o missionário e seu contexto cultural), e chegam ao "outro" (o nativo do país em que o missionário passa a viver), torna-se importante visualizar como tem se dado a busca por um diálogo não colonialista dentro desse processo. Os conflitos existirão, afinal, são eles que constroem as fronteiras que consideramos como sendo saudáveis. O que constitui o maior desafio é como levar os conflitos, depois de terem sido experienciados, a serem superados, sempre com o objetivo de se criar um relacionamento genuíno e que traga um equilíbrio ao ethos. Na revista Adventist Frontiers, é possível ver como as diferenças entre o "eu" e o "outro" levam à construção tanto de conflito quanto de fronteiras, o que afeta não só a identidade adventista do missionário, pelo ambiente islâmico-asiático ser tão diferente e desafiador, no qual o cristianismo representa um grupo quase inexistente, ${ }^{9}$ quanto também ajuda a delimitar a construção do "outro", nesse caso, o muçulmano que entra em contato com os missionários adventistas. E é essa construção da identidade que buscaremos analisar na seção seguinte.

9 Tal informação pode ser vista em: https://joshuaproject.net/countries/TU. Acesso em: 12 out. 2018. 


\section{Análise da Revista Adventist Frontiers}

Como já delimitado, o objetivo da presente pesquisa foi buscar uma relação de tendência entre a publicação dos relatos na revista da AFM e a construção de conceitos "eu-outro" que mostrassem algum tipo de conflitos. Nossa intenção era, a partir desses relatos, construir uma linha de pensamento que demarcasse como são vistas, na revista, as fronteiras entre as identidades ocidentais versus asiática e do missionário versus do nativo. Para se fazer mais claro o escopo da pesquisa, iniciamos esta análise relatando uma descrição quantitativa (Tabela 1) com os dados gerais identificados e mostrando quais deles foram realmente considerados.

Observa-se que, durante a última década, mais de 4.752 relatos de missionários em diversos continentes foram compartilhados durante todos os meses na revista. Desses, 528 pertencem às três famílias de missionários voluntários na Turquia. Um número expressivo, se levarmos em consideração que essas famílias representam apenas $10 \%$ do total de pessoas que atuavam com missões transculturais pela AFM durante o período analisado.

Tabela 1: Revista Adventist Frontiers (2007-2017).

\begin{tabular}{c|c|c}
\hline Relatos gerais & Relatos da Turquia & Relatos selecionados \\
\hline 4.752 & 528 & 132 \\
\hline
\end{tabular}

Fonte: Tabela produzida pelos autores.

A cada edição durante o período analisado, mais de 30 histórias foram compartilhadas, vindo de diferentes continentes, em ambos os hemisférios do globo. Como a Turquia representou um número expressivo de relatos (Tabela 1), cremos ser um importante pilar a ser pesquisado e entendido neste artigo. Devido à hegemonia religiosa mulçumana, ela nos traz um contexto relevante para entender como funciona a construção da relação entre o "eu" (missionário) e o "outro" (nativo). Entre os relatos mensais da Turquia, foi tomada a decisão de selecionar um artigo a cada revista mensal. O critério de seleção foi o relato que mais proporcionava detalhes da construção do ethos entre a realidade do missionário e os cidadãos turcos, revelando algum tipo de conflito. Após a devida análise de todas as histórias, 132 relatos foram escolhidos, o que cremos ser um recorte metodologicamente significativo. 
Após a análise de todo o material e dessa definição dos relatos selecionados, encontra-se a seguir a Tabela 2, que foi dividida em quatro grupos que definem parcialmente retratos e conflitos vividos por essas famílias missionárias no relacionamento entre o "eu" e o "outro". Identificou-se que diferentes comportamentos poderiam ser construídos desses retratos e conflitos vividos por essas famílias. Entre eles, o que mais se destacou foi a dificuldade de ver o "outro" como "outro". Pode-se observar que limitações são evidentes nesse processo de descoberta e construção em várias das histórias compartilhadas. Em segundo lugar, foi classificado o grupo de histórias do "eu" em suas dificuldades de se encaixar no mundo do "outro", já que este é tão diferente em seus valores e costumes. Esses dois grupos iniciais de relatos parecem se completarem, pois o primeiro considera a dificuldade de aceitação do "outro", já no segundo vemos a dificuldade do "eu" de encontrar lugar nesse novo mundo. Aqui temos um processo dialógico de construção identitária. Lembrando que tais relatos não são de pessoas diferentes, mas das mesmas famílias que se encontram em constantes mutações desde o início da missão, momento em que elas ainda não têm muita noção do que enfrentarão, até o fim dos dias que elas passarão ali naquela "terra distante".

Mais à frente, o grupo que se destacou foi aquele em que o "eu" busca apresentar essa nova religião aos nativos. Mas aqui parece já existir uma maturidade e uma autocrítica maiores perante as próprias dificuldades dessa missão, e os missionários refletem as dificuldades constantes e se policiam para não permanecer no mesmo desafio de seus antepassados: tornar-se um colonizador tanto em suas palavras quanto em suas motivações. Por último, destacou-se o grande conflito da insegurança física e psicológica, em uma região em que a liberdade e a segurança têm características bem diferentes de sua terra de origem, trazendo assim limitações significativas no processo de busca e de tentar encontrar o "outro". 
Tabela 2: Retratos e conflitos (2007-2017).

\begin{tabular}{|c|c|c|c|c|c|c|c|c|c|c|c|c|}
\hline $\begin{array}{l}\text { Retratos e } \\
\text { conflitos }\end{array}$ & 2007 & 2008 & 2009 & 2010 & 2011 & 2012 & 2013 & 2014 & 2015 & 2016 & 2017 & TOTAL \\
\hline $\begin{array}{l}\text { A dificulda- } \\
\text { de de ver o } \\
\text { "outro" como } \\
\text { "outro" }\end{array}$ & 3 & 2 & 1 & 2 & 3 & 2 & 2 & 4 & 3 & 3 & 3 & 28 \\
\hline $\begin{array}{l}\text { A dificuldade/ } \\
\text { vontade do } \\
\text { "eu" de se } \\
\text { encaixar no } \\
\text { mundo do } \\
\text { "outro" }\end{array}$ & 2 & 4 & 6 & 1 & 4 & 3 & 3 & 3 & 2 & 1 & 1 & 30 \\
\hline $\begin{array}{l}\text { A dificuldade } \\
\text { de mudar a } \\
\text { religião do } \\
\text { outro, sem ser } \\
\text { colonizador }\end{array}$ & 5 & 3 & 4 & 3 & 3 & 2 & 3 & 3 & 2 & 6 & 4 & 38 \\
\hline $\begin{array}{l}\text { A dificuldade } \\
\text { em se ter segu- } \\
\text { rança (física ou } \\
\text { psicológica) no } \\
\text { encontro/busca } \\
\text { entre o eu e o } \\
\text { outro }\end{array}$ & 2 & 3 & 1 & 6 & 2 & 5 & 4 & 2 & 5 & 2 & 4 & 36 \\
\hline
\end{tabular}

Fonte: Tabela produzida pelos autores.

Em todos os casos, quadros sociais sobre a relação "eu-outro" são continuamente formados e aqui analisados a partir da forma de seu relato textual, o que acaba por corroborar que a visão identitária que temos tanto de nós mesmos quanto dos outros é, como já argumentamos na parte bibliográfica do presente trabalho, essencialmente relacional. Nenhuma categoria teve uma força maior do que a outra, mostrando esse dialogismo identitário como ele foi percebido pelos missionários. O "outro" em nenhum momento deixa de ser diferente, mas passa com o tempo a ser menos 
"estranho" e mais "familiar". Já o "eu" acaba por ser relegado muitas vezes a um grau de pequenez. Quando o missionário sai de sua terra e vai para a Turquia, ele, na maior parte das vezes, acha que conseguirá mais resultados de modificações identitárias no "outro" do que os que ele encontra com o passar dos anos. Assim, resta ao missionário entender que é ele quem mais muda dentro dessa convivência dialógica.

Dos dados identificados na Tabela 2, foram selecionados alguns exemplos para cada grupo que se enquadra nesses retratos de conflitos entre o "eu" e o "outro". O objetivo foi dar ao leitor uma melhor compreensão dessas experiências vividas. Por questões de segurança não se mencionaram os nomes dos autores dos relatos. O objetivo maior é extrair essas falas e não a identificação dos personagens, como já mencionado na metodologia. Foram extraídas de todas as informações compartilhadas as que mais se destacaram no relato histórico, movido pela disposição de compartilhar essa relação do "eu" com o "outro". E são elas que mostram esse retrato mais claro sobre a visão ocidental de uma região asiática (a Turquia, no caso).

\subsection{A dificuldade de ver o "outro" como "outro"}

Como já dito, foram catalogadas no primeiro grupo todas as citações que claramente mostram um conflito quanto à dificuldade do missionário em entender ou aceitar o turco dentro de sua cultura, visão de mundo, manias ou estruturas políticas, econômicas e sociais. A questão aqui sempre é de estranhamento do "outro", a partir do seu local de existência. Um peregrino chega a uma nova terra, querendo contar as boas-novas que ele acredita possuir, mas a realidade se faz presente e acaba por construir problemas fronteiriços: aceitar o outro e, ao mesmo tempo, saber quem se é. Ou seja, não perder sua essência identitária, mas se abrir para o outro. Esses são os principais desafios encontrados a todo momento, principalmente pelos novos missionários. Assim, colocamos a seguir uma demonstração do que elencamos na Tabela 2 de maneira geral. Aqui mostramos algumas histórias sobre a capacidade de parte dos missionários na busca em enxergar o nativo como ele realmente é, com seus valores e contribuições.

Para começar a ilustrar a discussão com alguns exemplos selecionados, podemos ir diretamente para a edição de junho de 2011, na página 44 (tradução dos autores), momento em que um dos missionários compartilha uma história e conclui com um interessante apelo para oração, por parte do leitor da revista. Vamos à história: 
"Eu não sou uma muçulmana de verdade", disse Serin, uma mãe de trinta e poucos anos que havia vindo ao nosso estudo bíblico pela primeira vez. "Digo, eu acredito em Deus e tudo mais..." Sua dicção é muito boa e ela fala bem rápido. Achei que ela poderia ser uma boa pessoa para espalhar as boas-novas. Seu marido tinha vindo às nossas últimas reuniões e ouvido atentamente as lições que adaptamos àquela cultura. Eles estão dispostos a pensar além dos limites daquilo que lhes foi ensinado. O assunto chegou ao estado pecaminoso do ser humano, um ponto crucial para os muçulmanos, já que eles não acreditam que o homem é egoísta por natureza e não aceitam a ideia de que o salário do pecado é a morte. Então, não precisam de um Salvador. Apesar de Serin dizer que não é muçulmana de verdade, sua ideologia é muito muçulmana. "Acho que as pessoas fazem apenas aquilo que são ensinadas a fazer e aquilo que veem." Perguntamos a ela: "Quem ensina uma criança de três anos a mentir? Ninguém. Mas ela mente. Por quê?" Podemos observar a concentração no rosto de Serin. Será ela capaz de pensar além da ideologia muçulmana? Por favor, ore por Serin e os outros amigos do nosso grupo. ${ }^{10}$

No exemplo citado, fica evidente a maneira como esse missionário vê o "outro" em sua construção religiosa, mostrando sempre a tensão entre o aceitar e o recusar, indicando claramente a visão de existir uma cosmovisão diferente entre eles. Aqui temos um vislumbre se não de uma criação de fronteiras entre o "eu-outro", pelo menos de uma percepção da existência dessas fronteiras e de como ela pode ser transitória na percepção do autor. Afinal, ao final do parágrafo, ele pede que os leitores orem por esse "outro". Isso mostra que ele acredita que a pessoa pode modificar sua visão e passar a pensar mais igual ao ocidental.

Outra questão que aqui pode ser percebida é quanto à situação de uma narrativa identitária ser considerada como mais errada em sua concepção de religião do que a outra - é a partir dessa percepção que o missionário parece

10 Original: 'I'm not really a Muslim per se,' said Serin, a thirty-something mom who attended our home Bible study for the first time. 'I mean, I believe in God and all that...' Her diction is good, and she speaks incredibly fast. I thought she would make a good newscaster. Her husband had come to two previous home meetings, listening carefully to the culturally contextualized lessons we have been writing. They are willing to think outside the limits of what they have been taught. The subject turned to the sinful state of man, a crucial point for Muslims. They don't believe man is selfish by nature, and they do not accept the idea that the wages of sin is death. Thus, they have no need for a savior. Even though Serin says she is not a Muslim per se, her ideology is very Muslim. 'I think people only do what they are taught and what they see.' We asked her, 'Who teaches a three- year-old to lie? No one. But they do it. Why?' We see the concentration in Serin's face. Will she be able to think outside Muslim ideology? Please pray for Serin and the others in our group". 
se sentir frustrado em não conseguir mudar tal quadro. Claro, essa realidade é normal e esperada, afinal, sairia o missionário de seu país e iria para outro local se ele não cresse ter algo de novo e de verdadeiro para contar àqueles que ali ele encontrará? Dentro disso, ver o outro como ele é se torna um conflito, uma tensão permanente. Ao mesmo tempo em que vivemos um limiar de possibilidade quanto a um pensamento imperialista (o "outro" precisa mudar sua religião, abandonando-a e crendo tal como eu creio) e um pensamento que considera o "outro" como "outro", mesmo que não se concorde com ele (quero que ele mude, mas, se não mudar, só me resta orar). É justamente dentro dessa tensão que cremos estar a formação de fronteiras sociais de identidade, as quais aqui podemos perceber se olharmos para além do mero relato inicial, pensando um processo dialógico que não considere apenas um dos lados, mas os dois ao mesmo tempo.

Em outro momento, esse mesmo missionário descreve sua experiência em se exercitar com o intuito de alcançar a busca em ver o "outro" como "outro", mostrando como essa construção da relação tem também o seu lado prazeroso quando esse "outro" é aceito, entendido e passa a trabalhar com o missionário. Mesmo que isso não seja algo simples e natural para alguém que ainda se considere tão distante desse "outro", devido às diferenças culturais agora mais claras. Com isso, não se perde a noção de se evangelizar o pensamento do "outro", mas é de se perguntar se aqui temos uma questão totalmente imperialista ou se temos o caso de existir uma fronteira menos delimitada, que pode pender para um ou para o outro lado de maneira fácil, a depender dos contextos sociais relacionados. Em novembro de 2012, na página 27 (tradução dos autores) se relata:

A experiência de uma nova cultura é fantástica. Ela nos ajuda a compreender a mentalidade dos turcos e a entender como as pessoas pensam. Agora que passamos pelo Ramadã, novas perguntas surgiram em nossa mente. Nossa mentalidade ocidental nem sempre consegue entender o pensamento racional do Oriente. Mas, quanto mais imergimos na cultura turca, mais desejamos entender o povo turco, a fim de que possamos construir relações pessoais e assim comunicarmos a beleza do evangelho na mentalidade e linguagem deles. ${ }^{11}$

11 "It's amazing to experience a new culture. It helps us understand Turkish mindset and gives us insight into how people think. Now that we have been through a Ramazan, it has opened our minds to new questions. Our Western mindset doesn't always understand the rational of Eastern thinking. As we spend time immersed in Turkish culture, it is our desire to understand Turkish people so we can develop deep personal relationships and thus communicate the beauty of the Gospel in their mindset and language." 
Analzira Nascimento (2009, p. 474) afirma, sobre essa vida na fronteira, que, ao estar longe de seu espaço geográfico e cultural, o missionário sofre uma interculturação, pois ele tanto assimila traços de uma nova cultura quanto aceita novos traços. Em outras palavras, "suas concepções e paradigmas estão sendo revistos". Aos poucos se supera o sentimento de não pertença e começa a ser aceito no novo mundo, mas o passado ainda está ali, sempre com ele. Como Nascimento (2009, p. 474) nos lembra, "a coragem de romper e arriscar em direção ao outro traz experiências dolorosas. Buscar o equilíbrio para viver intensamente o presente é o grande desafio". E tudo isso é possível visualizar nos relatos desse primeiro grupo; mesmo que aqui tenhamos colocado apenas dois exemplos, essa realidade se faz presente em todos eles. Afinal, para se entender e aceitar o "outro" é primeiro preciso aceitar e entender o próprio "eu". E isso se faz sempre de maneira mais intensa e mesmo paradoxal quando as fronteiras são repensadas, como na vivência missionária em outro país e cultura. O que temos nesses relatos, portanto, não é apenas a construção de um pensar quem é turco a partir de uma visão ocidental, mas um pensar o próprio contexto ocidental no qual o missionário se formou e se moldou por tanto tempo, isso a partir do encontro dele com o "outro". E se pensar e se repensar é justamente o escopo da categoria que abordaremos a seguir.

\subsection{A dificuldade/vontade do "eu" de se encaixar no mundo do "outro"}

Outra fase da construção do ethos que aqui articulamos é o desejo do missionário em fazer parte do mundo novo em que ele está inserido. Pequenos detalhes demonstram esse sentimento que ajuda a construir no dia a dia o respeito ao mundo do "outro".

No exemplar de agosto de 2011, página 9 (tradução dos autores), um dos missionários compartilha seu olhar daquilo que é falsificado na Turquia e é comercializado com um bom nível de qualidade, mesmo sendo falsificado. Ele diz: "Vivemos em um país cheio de imitações baratas. Você pode pegar o metrô e ir comprar Nikes, All Stars e Ray-Ban falsificados". ${ }^{12}$ Em tal relato o missionário se abre para o que existe naquele novo local, mas ainda vemos que a cultura ocidental acaba por ser sua referência em se assustar com o "novo". O interessante aqui é que a crítica nem é tanto à falsificação em

12 "We live in a land led with cheap imitations. You can get off the metro and buy fake Nikes, Converse All Stars, and Ray Ban [sic] sunglasses." 
si, visto que ele até elogia a qualidade dos produtos. Claro que é preciso relativizar essa construção da cultura do "outro", pois o ponto no texto é espiritualizar a realidade, tirando lições dela para a aplicação na vida religiosa dos leitores, e não tanto fazer uma crítica ou uma construção social; mas ela acaba, mesmo assim, por emergir do discurso que narra o que está ocorrendo em sua nova vivência. As experiências da rotina diária podem e devem ser referências para identificar o processo tanto de recusa quanto de aceite do "outro". E tais relatos começam a existir de maneira cada vez mais frequente, o que mostra que há vontade de realmente se adaptar à nova vivência, mas será apenas quando elas forem naturalizadas a ponto de não serem notadas pelo "eu" é que estarão concretizadas.

O contrário também é verdade, pois o outro tem o mesmo desafio quando o missionário lhe propõe algo "novo". Assim, ambos convivem com tal dificuldade. Uma experiência, encontrada na edição de fevereiro de 2012, p. 15 (tradução dos autores), ilustra isso muito bem:

Onur tem ouvido um sermão atrás do outro e parece gostar muito deles. Ele jejua durante o Ramadã e se considera muçulmano. Mas houve uma ocasião em que um crente testemunhou sobre como abandonou o islamismo e suas falsas ideias, então Onur saiu. "Por que ele está menosprezando minha religião?", ele disse. Mas continuou vindo à igreja. ${ }^{13}$

É bem interessante notar, nesse relato, como a construção do "eu", como processo identitário, é sempre maior do que pode parecer em um primeiro momento. Podemos pensar que a identidade religiosa é fácil de ser modificada. O missionário sai de sua terra na esperança de que esse processo seja fácil, ou que pelo menos seja possível de ocorrer com aqueles a quem ele entrará em contato, mas a realidade surge e mostra sua dificuldade. Com isso, o tempo se torna tanto desafio quanto remédio para a concretização desse relacionamento com o "outro". As diferenças se multiplicam nos objetivos estabelecidos, e o tempo acaba se confirmando em sua relatividade. O diálogo a seguir, registrado na revista do mês de abril de 2012, na página 20 (tradução dos autores), retrata essa compreensão do "eu" quanto ao tempo de decisão do "outro":

13 "Onur has been listening to sermon after sermon and seeming to enjoy them very much. He fasts during Ramadan and considers himself a Muslim. Once, when a believer gave a testimony about coming out of Islam and abandoning all those false ideas, Onur walked out. 'Why is he putting down my religion?' he said. But he kept coming to church." 
"Barnabas, levei 30 anos para pensar como penso hoje. Conheço você há apenas três anos. Não dá para desfazer 30 anos em apenas três.” Essa declaração me atingiu em cheio enquanto conversava com meu amigo Zafer, um eletricista. Ele é o homem mais honesto da nossa igreja. Ele ora comigo para Jesus. Confessa que Jesus é o Filho de Deus. Ele me diz que desistiu do Alcorão porque "é um livro que não leva a lugar nenhum". Ele tem vindo fielmente ao nosso culto de sábado com sua esposa ucraniana há três anos. Mas ainda não está pronto para tomar uma decisão. Para mim, sua declaração foi a descoberta de que a verdadeira conversão, acompanhada de uma mudança de visão de mundo, leva tempo - muito tempo. Zafer é tão honesto que não quer ser convertido apenas pela metade. ${ }^{14}$

Podemos reafirmar que a identidade é forjada socialmente e ancora o ethos do indivíduo, o qual tem dificuldades para se modificar ontologicamente. Mudam-se questões epidérmicas, como frequentar um novo ambiente de culto, mas se tem dificuldades em mudar por completo sua identidade, o que é visto no primeiro exemplo com a expressão "minha religião" e no segundo com a frase "não dá para desfazer...". Mesmo existindo boa vontade, há dificuldades do "eu" em se encaixar no mundo do "outro", seja esse "eu-outro" qual for.

\subsection{A dificuldade de mudar a religião do outro, sem ser colonizador}

David Bosch (2002) realizou uma interessante pesquisa analisando os diferentes paradigmas da missão ao longo da história da igreja e termina a sua obra dando os "contornos" de um novo paradigma missionário. A conclusão dos seus estudos se limita a revelar alguns "elementos deste suposto paradigma emergente". Ele faz um diagnóstico do atual quadro da missão, que também é uma síntese da sua tese principal, afirmando categoricamente que "o empreendimento missionário moderno em sua íntegra está tão contaminado por sua origem no colonialismo ocidental e sua estreita associação com ele que é irremediável; temos que encontrar uma imagem completamente nova hoje" (BOSCH, 2002, p. 617).

\footnotetext{
14 “'Barnabas, it's taken me 30 years to think like I do. I have known you for only three years. I can't undo 30 years in three years.' This statement struck me as I sat and talked with my dear friend Zafer, a legally blind electrician. He is the most honest man in our church. He prays with me to Jesus. He confesses Jesus to be the Son of God. He tells me he gave up on the Quran because 'it is a book that drives to nowhere.' He has attended our Sabbath service with his Adventist Ukranian wife for three years very faithfully. Yet, he isn't ready to make a decision. For me, his statement was a powerful insight that true conversion with deep worldview shift takes time - lots of time. Zafer is an honest enough man that he doesn't want to be only half converted."
} 
Tocar o "outro" é uma das coisas mais importantes de todo o processo aqui discutido; por isso, reafirmamos a construção anterior sobre a necessidade, sim, de se mudar algo no "outro" - afinal, cremos ser essa parte primordial do evangelho e também da construção dialógica da identidade. Entretanto, não podemos apenas despejar algo no "outro" sem nos abrirmos para contrapartidas; é necessário sempre existir um diálogo em amor e, para isso, precisamos nos colocar constantemente no lugar do "outro" em uma genuína busca por alteridade. Em junho de 2009, na página 28 (tradução do autor), encontra-se a seguinte declaração: “Mas muitos turcos consideram nosso desejo de compartilhar Jesus como mais uma forma de imperialismo. Veem nossa amizade apenas como mais um meio de espalhar a religião e cultura ocidentais, com o intuito de destruí-los". ${ }^{15}$ É interessante notar nessa declaração que o missionário da AFM em um ambiente asiático, ou seja, inter-religioso, confirma esse sentimento do outro em se sentir colonizado pela religião cristã. $O$ fato de declarar isso no periódico mostra que existe um conflito dialógico positivo, indicado ao se exteriorizar formas de ao mesmo tempo respeitar a opinião do outro e também de ser capaz de comunicar algo.

$\mathrm{Na}$ citação a seguir, o autor descreve diferenças culturais religiosas que confirmam o cuidado ao dialogar com o outro e as dificuldades naturais encontradas. Gera-se seguramente conflitos, em que o respeito e a sensibilidade se tornam elementos vitais, minimizando a busca por uma transição de religião por parte do nativo, mas evitando ao máximo o comportamento colonizador do missionário. Em novembro de 2011, na página 7 (tradução dos autores), temos a seguinte reflexão por parte do missionário:

“A prova está no texto!", exclamou o pastor com firmeza. "É tão clara quanto a luz do dia. Não há como não entender o seu verdadeiro significado.” Eu estava sentado ali ouvindo o sermão e pensando: Ele está certo. É óbvio. Como alguém poderia chegar a outra conclusão? Mas talvez não fosse tão clara para alguns. Talvez eles precisassem de uma explicação melhor, de contextualização, de uma experiência anterior para apoiar essa verdade, ou, em termos transculturais, uma visão de mundo diferente. Enquanto falamos verdades que consideramos simples e fundamentais, é fácil supor que pessoas de outras culturas estejam entendendo o que estamos lhes dizendo, mas geralmente não é o que acontece. Por exemplo, se disséssemos a um turco: "Deus é amor", ele poderia concordar, mas provavelmente não teria a compreensão desse amor expresso

15 "But many Turks consider our desire to share Christ simply another form of imperialism. They view our friendliness as just a means to spread our Western religion and culture in preparation for their overthrow." 
na vida, morte e ressurreição de Jesus Cristo. Não compreende esse amor no contexto da constante busca de Deus pelo homem. Quando dizemos: "Você pode confiar em Deus porque Ele se importa com você", será que eles realmente acreditam? Pois creem que tanto o bem quanto o mal vêm de Deus. Deus não só permite que as coisas ruins aconteçam, como essa é a vontade Dele e o seu destino. Nessa visão de mundo, uma criança que morre num acidente de carro é pela vontade de Deus. Afinal, Ele escreveu o destino daquela criança! Será que essa mentalidade também dificultaria sua visão de que Deus é amor? Quando dizemos: “Jesus morreu por seus pecados e superou a morte ao ressuscitar dos mortos, a fim de que você também possa viver eternamente", os turcos conseguem realmente entender o que estamos dizendo? A visão de mundo turca não permite a morte vicária. Uma pessoa não pode morrer pelos pecados de outra. Sem mencionar que Deus não permitiria que coisas ruins acontecessem com seus profetas. Pois não faz sentido que um profeta nascido sem pecado, nascido de um milagre e que fez tantos milagres, fosse assassinado. Com certeza foi outra coisa que aconteceu. Ou Deus o levou direto para o céu e a história toda é mentira, ou Deus fez com que a pessoa que morreu na cruz parecesse Jesus. Alguns muçulmanos até acreditam que quem morreu na cruz foi Judas. (Uma nota adicional: não é interessante que tanto Judas quanto Jesus morreram num madeiro? Judas se enforcou numa árvore por causa da culpa que sentia, enquanto Jesus permitiu ser assassinado na cruz por causa de nossa culpa. Verdades poderosas!) Sob essa luz, como os missionários da AFM garantem que os turcos, himbas, malinkes e gorkhas estejam mesmo ouvindo o que tentamos lhes dizer? Estudamos a cultura deles, fazemos analogias baseadas em suas histórias, tradições e vida cotidiana, e usamos essas analogias para provocar uma mudança em sua visão de mundo e explicar as verdades do evangelho. ${ }^{16}$

16 "'The proof is in the text!' the pastor adamantly proclaimed. 'It is as plain as the nose on your face. There shouldn't be any doubt as to its true meaning.' I sat there listening to the sermon and thought to myself, $\mathrm{He}$ is right. It is obvious. How could someone come to any other conclusion? But perhaps for some people it wouldn't be obvious. Maybe they would need a better explanation, a context, a previous experience to hang this truth on, or, in cross-cultural ministry terms, a different worldview. While speaking truths we consider simple and fundamental, it is easy to assume that people from other cultures understand what we are trying to tell them, but this is often not the case. For example, when we say to a Turk, 'God is love', he would agree. But he would likely have no understanding of God's love as expressed in the life, death and resurrection of Jesus Christ. He doesn't understand it in the context of God's constant pursuit of man. When we say, 'You can trust God because He cares about you,' do they really buy it? They think that both good and bad come from God. He doesn't just permit bad things to happen; it is actually His will and your destiny. In this worldview, a child dying in a car accident is God's will. After all, He wrote the child's fate! Would that mindset make it hard for you to believe that God is love? When we say, 'Jesus died to pay the penalty for your sin and conquered death by coming back to life so that you, too, could live forever,' can Turks really grasp what 
Essa reflexão sobre a existência de diferentes cosmovisões e a sabedoria que precisa existir para que haja relacionamento entre os envolvidos é um bom marco no texto citado. $\mathrm{O}$ autor mostra uma preocupação em entender o outro em seu contexto, compreendendo o que diferencia o "eu" do "outro". Novamente, como é de se esperar, o "outro" é alguém a ser convencido e ensinado. Mas essa parece a própria razão de ser do missionário. Se ele não quisesse convencer o "outro" de sua verdade, qual motivo o levaria a sair de sua casa e de seu conforto para viver sua "missão"? Entretanto, o equilíbrio parece a grande questão a ser buscada; mas como equilibrar o aceitar com o recusar? Aceitar a diferença, mas se recusar esquecer o motivo que o levou até aquele local. É preciso haver uma transmissão da memória religiosa que respeite o "outro", transmissão que busca equilíbrio entre o "outro" e o "eu".

\subsection{A dificuldade em se ter segurança (física ou psicológica) no encontro/busca entre o "eu" e o "outro"}

Devido aos perigos de se comunicar o cristianismo em um país islâmico, uma representação constante é aquela que relata conflitos de insegurança quanto à dificuldade de enxergar o "outro" não como um delator ou investigador. Essas são memórias encontradas em várias citações. $\mathrm{Na}$ construção do "eu" e o "outro", a maior dificuldade é da insegurança entre o aceitar o "outro" a ponto de correr o risco de perder o "eu". Aqui essa questão é elevada a uma potência maior e mais real do que apenas à questão psicológica construtora da identidade. Temos uma questão de insegurança política e social na Turquia, mas que serve para ilustrar todo o processo de construção identitária, em suas nuanças tangíveis e intangíveis. Entre

we are saying? The Turkish worldview doesn't allow for vicarious death. A person can't die for someone else's sin. Not to mention their conviction that God wouldn't allow bad things to happen to His prophets. It just doesn't make sense that a sinless prophet who was born by a miracle and performed all those miracles could be killed. Surely something else happened. Either God took him directly to heaven and the whole story is a lie, or the person who died on the cross was made by God to appear like Jesus. Some Turks even claim that Judas was the one who died on the cross. (As a side note, isn't it interesting that both Judas and Jesus died on trees? Judas killed himself because of the personal guilt he felt, while Jesus allowed himself to be killed because of our guilt. Powerful truths!) In light of this, how do AFM missionaries ensure that Turks, Himbas, Malinkes and Gorkhas really hear what we are trying to share? We study their culture, draw redemptive analogies from their stories, traditions and daily lives and use those analogies to build a foundation for worldview shift and to explain Gospel truths." 
as diversas citações, destacamos alguns relatos mencionados a seguir. Em primeiro lugar, a edição de março de 2012, página 40 (tradução dos autores), narra a seguinte história:

Parecia um dia como outro qualquer, até o telefone tocar. "Vamos nos encontrar ao meio-dia", disse uma voz baixinho e, então, click, desligou. $\mathrm{O}$ encontro estava marcado. Peguei os documentos e saí porta afora. Fui até o local combinado e esperei pacientemente. Depois de vários minutos, meu contato surgiu em meio à multidão e se aproximou do carro. "Entre rápido", eu disse. Ele entrou, olhando para ver se alguém tinha percebido, mas não havia ninguém. "Aonde você quer ir?", perguntei. "Dirija até a escola e pare lá em frente. Podemos conversar ali." Quando chegamos à escola, começamos a conversar. Quando vimos que estávamos seguros, pegamos os documentos e começamos a lê-los. E, então, o que você pensou quando começou a ler isto? Pareceu um filme de espionagem ou um livro de mistério? Bem, deixe-me decifrar o código para você: a chamada telefônica era do meu amigo Ibrahim. Os documentos eram duas lições. O encontro era um estudo bíblico. E sim, estudávamos no carro, em frente à escola dos filhos dele, enquanto as pessoas caminhavam por ali. Oramos, rimos, discutimos e tivemos um encontro com o Todo-Poderoso. ${ }^{17}$

A insegurança para um missionário é uma realidade tão presente na Turquia, e em boa parte do continente asiático, que o humor tem que se tornar um tempero para essa dificuldade, ajudando a construir a identidade ao superar, mesmo que momentaneamente, os medos e receios. Elementos que são regulares no Ocidente tornam-se grandes conflitos. Uma declaração publicada em abril de 2017, na página 16 (tradução dos autores), nos lembra o quão comum isso é, ao narrar que: “Também discutimos as muitas

17 "It started out just like any other day, and then the phone rang. 'Let's meet at 12:30 p.m.' a low voice said, and then, click, he hung up. The appointment was made. I grabbed the documents and headed out the door. Pulling up to the pick-up point, I waited patiently. After several minutes, my contact emerged from the crowd and approached the car. 'Get in quick,' I said. He got in, glancing around to see if anyone had noticed him. The coast was clear. 'Where do you want to go?' I asked. 'Drive to the school and pull up front. We can talk there.' After arriving at the school, our conversation began. When we knew it was safe, we pulled out the documents and began reading them. So, what did you think when you started reading this? Did it remind you of a spy movie or a mystery novel? Let me decipher the code for you: The call was from my friend, Ibrahim. The documents were two lesson books. The meeting was a Bible study. And yes, we studied in the car, in front of his kids' school while people walked by us. We prayed, laughed, discussed and had a divine appointment with the Almighty." 
questões e preocupações dos missionários que estão sob nossos cuidados, como ataques espirituais, ameaças locais, conflitos dentro da equipe e muitas outras coisas". ${ }^{18} \mathrm{Já}$ em outubro de 2016, na página 7 (tradução dos autores), é dito que o direito de ir e vir ficou comprometido, pois "foi anunciado que os militares declararam a lei marcial e que ninguém podia sair na rua. Era tempo de decisão!"19

E o maior desafio de insegurança que um ser humano pode passar é aquele que não está limitado ao próprio "eu", mas se direciona para o “outro". Separação, abandono, desprezo e símbolo de vergonha para os familiares daqueles que tomaram a decisão de mudar de religião, são os elementos que se destacam, e isso não é ruim apenas para o nativo, mas também um grande desafio para o missionário, que precisa trabalhar com as consequências e dar suporte ao novo converso. Em dezembro de 2015, na página 33 (tradução dos autores), um dos missionários afirma isto na revista Adventist Frontiers: "A escolha dela em seguir Jesus implica na separação da sua família, o que lhe causa muita ansiedade. Tem sido uma caminhada difícil", ${ }^{20}$ E realmente isso define bem toda a construção identitária "eu-outro": é uma caminhada difícil.

\section{Considerações finais}

Portanto, os relatos e a discussão que foram mostrados até aqui reforçam a importância de incluir uma reflexão sobre essa visão do que é o outro no contexto da missiologia, já que o modelo vigente está, muitas vezes, mais preocupado com o cumprimento de programas denominacionais do que em construir pontes entre pessoas. Poderia ser estabelecida uma meta de trabalho pela construção de uma concepção de fronteira que retome o diálogo e a aceitação das diferenças, recuperando, assim, a marca que a missiologia já teve de ser relacional e encarnacional. É importante que seja construído um conhecimento multicultural, que vise à rejeição de uma visão de supremacia por parte do missionário, pois isso ajudaria a combater o vício de reproduzir sua própria história e enxergar a cultura do outro a partir

18 "We also discuss the many issues and concerns of the missionaries under our care, such as spiritual attacks, local threats, conflict within teams and many other things."

19 "Then it was announced that the military had declared martial law, and no one was allowed on the streets. decision time!"

20 "Her choice to follow Jesus means separation from her family, which causes her great anxiety. It has been a hard road." 
de sua própria visão de mundo. Dessa forma, as inseguranças criadas no encontro com as diferenças da cultura do "outro" poderiam ser amenizadas (NASCIMENTO, 2013).

$\mathrm{Na}$ concepção cristã, a motivação deve ser sempre a glória de Deus. Servir a Deus é tentar enxergar o "outro" a partir dos olhos Dele, estabelecendo uma relação de compreensão e diálogo, amando-o como Jesus. Assim, se conquista o direito de compartilhar a fé, pois já houve a construção de uma relação de confiança e respeito, e, por vezes, de admiração. É preciso respeitar, não invadir a casa do outro, mas, sim, reconhecer a individualidade e dignidade de cada sociedade, sendo humilde e percebendo que o outro também tem contribuições a fazer e coisas a ensinar, não inferiorizando as diferenças (NASCIMENTO, 2013). Também é importante não se perder de vista que, no final de tudo, o que o missionário quer é ensinar e transmitir uma memória religiosa. E isso não é errado, se começar e se mantiver com o pressuposto correto: a alteridade.

Cremos que a AFM, na revista analisada, se preocupa com essas questões. $\mathrm{O}$ artigo é de reflexão, sim, mas também de crítica para que esse tipo de atitude continue e aumente cada dia mais. Mas este artigo também é de celebração, pois, ao final dos textos e das linhas que lemos, a preocupação com o outro é demonstrada e está presente na maior parte dos materiais analisados. Até mesmo aqueles que poderiam depor contra isso, se olharmos bem, são de missionários recém-chegados. É importante notar que a maior parte dos artigos aqui analisados vêm das mesmas dez famílias que estiveram na Turquia na última década. É natural perceber que, quando eles chegam ao campo, o sentimento é de colonização, mas, ao se passar os meses e os anos, a impotência começa a se impor, o que ajuda a conscientizar da importância do diálogo. E isso explica o motivo de o resultado encontrado ter sido um misto da evolução do encontro e da junção com o outro, em associação com um estranhamento sobre quem é esse outro e quem o missionário espera que ambos sejam após tais encontros. Em suma, dá para mostrar empiricamente o que argumentamos algumas vezes: a identidade é (sempre) relacional.

\section{Referências}

AGAMBEN, G. Nudez. Lisboa: Relógio D’Água, 2010.

ALVES, R. Religião e repressão. São Paulo: Loyola; Teológica, 2005.

BARDIN L. Análise de conteúdo. Lisboa: Edições 70, 1977. 
BOSCH, D. J. Missão transformadora: mudanças de paradigma na teologia da missão. 4 . ed. São Leopoldo: EST; Sinodal, 2002.

BULL, M.; LOCKHART, K. Seeking a sanctuary: Seventh-Day Adventism and the American dream. Bloomington: Indiana University Press, 2007.

DUSSEL, E. 1492 - O encobrimento do outro: a origem do mito da modernidade. Petrópolis: Vozes, 1993.

FOLLIS, R. Memória, mídia e transmissão religiosa: estudo de caso da Revista Adventista (1906-2010), 2017, 231f. Tese (Doutorado em Ciências da Religião) - Universidade Metodista de São Paulo. São Bernardo do Campo, São Paulo.

FRANCO, M. O que é análise de conteúdo. São Paulo: PUC, 1986.

GAUSTAD, E. S. The rise of Adventism. Grand Rapids: Eerdmans, 1986.

GREENLEAF, F. Terra de esperança: o crescimento da Igreja Adventista na América do Sul. Tatuí: Casa Publicadora Brasileira, 2011.

GUIMARAIS, M. Turquia: dicotomias e ambivalências de uma possível potência regional, 2007, 230f. Dissertação (Mestrado em Geografia) - Universidade de São Paulo. São Paulo.

KNIGHT, G. Adventismo: origem e impacto do movimento milerita. Tatuí: Casa Publicadora Brasileira, 2015.

KNIGHT, G. Em busca de identidade: O desenvolvimento das doutrinas adventistas do sétimo dia. Tatuí: Casa Publicadora Brasileira, 2005.

KNIGHT, G. Uma igreja mundial: breve história dos adventistas do sétimo dia. Tatuí: Casa Publicadora Brasileira, 2000.

LESSA, A.; SILVA, E.; FONSECA-SILVA, M. Cristianismo e marxismo: ethos no pacto de Lausanne (1974). In: Encontro Estadual de História, 8, 2016, Feira de Santana. Anais... Feira de Santana: UEFS, 2016, p. 1-10. Disponível em: https://goo.gl/mEYT6A. Acesso em: 3 out. 2018.

LOUGHBOROUGH, J. N. O grande movimento adventista. Engenheiro Coelho: Adventist Pioneer Library, 2014.

MARTINS, J. Fronteira: a degradação do Outro nos confins do humano. São Paulo: Hucitec, 1997.

MOLINA, D. F. ¿El papa del fin de la Era Constantiniana?. Cuestiones Teológicas, v. 44, n. 102, p. 347-372, 2017. Disponível em: https://goo.gl/LNp8J2. Acesso em: 3 out. 2018.

NASCIMENTO, A. A identidade cultural do missionário. In: WINTER, R. D. HAWTHORNE, S. C.; BRADFORD, K. D. Perspectivas no movimento cristão mundial. São Paulo: Vida Nova, 2009. p. 473-475.

NASCIMENTO, A. Missão e alteridade: descolonizar o paradigma missiológico, 2013, 165f. Tese (Doutorado em Ciências da Religião) - Universidade Metodista de São Paulo. São Bernardo do Campo, São Paulo.

PESAVENTO, S. (Org.). Fronteiras do milênio. Porto Alegre: Ed. da Universidade, 2001. 
ROCHA, D.; DEUSDARÁ, B. Análise de conteúdo e análise do discurso: aproximações e afastamentos na (re)construção de uma trajetória. Alea, v. 7, n. 2, p. 305-322, 2005.

SCHÜNEMANN, H. E. S. O tempo do fim: uma história social da Igreja Adventista do Sétimo Dia no Brasil, 2002. Tese (Doutorado em Ciências Sociais e Religião) - Universidade Metodista de São Paulo. São Bernardo do Campo, São Paulo.

SCHWARZ, R. W.; GREENLEAF, F. Portadores de luz: história da Igreja Adventista do Sétimo Dia. Engenheiro Coelho: Unaspress, 2016.

STRAUSS, A.; CORBIN, J. Pesquisa qualitativa: técnicas e procedimentos para o desenvolvimento de teoria fundamentada. São Paulo: Artmed, 2008.

TERRIN, A. N. O sagrado off limits: a experiência religiosa e suas expressões. São Paulo: Loyola, 1998.

Winter, R. D. HAWTHORnE, S. C.; BRADFORD, K. D. Perspectivas no movimento cristão mundial. São Paulo: Vida Nova, 2009.

WOODWARD, K. Identidade e diferença: uma introdução teórica e conceitual. In: SILVA, T. T. (Org.). Identidade e diferença: a perspectivas dos estudos culturais. Petrópolis: Vozes, 2014.

Submetido em: 9-11-2018

Aceito em: 2-12-2018 